\title{
Erratum to: Consumption of non-steroidal anti-inflammatory drugs in Serbia: a comparison with Croatia and Denmark during 2005-2008
}

Vesna Mijatović • Jelena Ćalasan • Olga Horvat •

Ana Sabo • Zdenko Tomić • Vukašin Radulović

Published online: 4 August 2011

(C) Springer-Verlag 2011

Erratum to: Eur J Clin Pharmacol (2011) 67:203-207

DOI 10.1007/s00228-010-0951-x

Acknowledgements This study was supported by a grant from the Ministry of Science and Technological Development, Serbia (Grant no. 41012).

The online version of the original article can be found at http://dx.doi. org/10.1007/s00228-010-0951-x.

V. Mijatović $(\bowtie) \cdot J$. Ćalasan $\cdot$ O. Horvat $\cdot$ A. Sabo

Department of Pharmacology, Toxicology and Clinical

Pharmacology, Faculty of Medicine, University of Novi Sad,

Hajduk Veljkova 3,

21000 Novi Sad, Serbia

e-mail: mijatovic.vesna@yahoo.com

Z. Tomić

Department of Pharmacology, Faculty of Medicine,

Podgorica, Montenegro

V. Radulović

Republic Institute for Health Insurance of Serbia,

Belgrade, Serbia 